\title{
Engaging patients to improve equitable access to community resources
}

\author{
Simone Dahrouge PhD, Karen James RP, Alain Gauthier PhD, Francois Chiocchio PhD
}

Cite as: CMAJ 2018;190(Suppl 1):S46-S47. doi: 10.1503/cmaj.180408

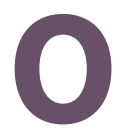

ntario has invested heavily in health-enabling communitybased resources such as self-management, falls prevention and caregiver support programs. ${ }^{1-4}$ Many are critically underused, ${ }^{5}$ especially by those with the greatest needs, ${ }^{6}$ because of barriers relating to literacy, language, transportation, income and other social factors. In addition, linguistic concordance between patient and provider is beneficial, ${ }^{7}$ yet many French-speaking Ontarians cannot find such resources in their language. In 2014, funded by a grant from the Canadian Institutes of Health Research Strategy for Patient-Oriented Research (SPOR), we undertook an initiative to improve equitable access to health-enabling community resources in the Champlain Local Health Integration Network (LHIN).

We established a regional partnership that included 15 individuals whose jobs or lives could be affected by, or could help influence, the work we were doing to help guide the initiative. The partnership comprised decision-makers, health care providers, various service providers and individuals with lived experience (e.g., an older female caregiver, a young man belonging to an ethnic minority group, and a woman with a history of mental illness and substance abuse). Informed by evidence, the partnership decided to implement patient navigation services in primary care practices to support patients in overcoming barriers to access and use community resources they needed.

We began testing this navigation model in 2016. The same year, OSSU (the Ontario SPOR SUPPORT [Support for People and PatientOriented Research and Trials] Unit) funded a randomized controlled trial (RCT) of the intervention in the Champlain and North East LHINs, prioritizing equitable access to language-concordant services. We added two francophone patient partners (individuals with lived experience) to ensure inclusion of that population's perspective in the trial, and created a similar partnership in the North East LHIN to inform the program implementation in that region.

We applied specific strategies to promote the active contribution of all partnership members, especially the patient partners. ${ }^{8}$ For example, we supported one patient partner (K.J.) to attend a masterclass on patient-oriented research, which she reported strengthened her understanding of her role within the partnership. ${ }^{9}$ Partnership members with lived experience attended provincial planning meetings and various scientific conferences, where the project was presented to gain a broader sense of the study's potential implications.

The Champlain partnership met every four to six months, with consultations with various members taking place between these

\section{KEY POINTS}

- Individuals with lived experienced were engaged in a partnership with other stakeholders throughout the research cycle of an innovation to improve access to health-enabling community resources.

- We applied specific strategies to promote the active contribution of individuals with lived experience, and these members have influenced decisions regarding the study design, implementation and evaluation.

- The open and respectful dialogue that took place across all members allowed for a much richer conversation and betterinformed decisions.

- We believe that, as a result of the partnership, the navigation model developed is much more likely to be responsive to patient needs and acceptable to care providers, and has greater potential for scalability by decision-makers.

meetings to inform their content. We ensured that members of each group attended the meetings. We tried to schedule these at convenient locations (e.g., wheelchair accessible) and times for patient partners, provided food and beverages, offered taxi chits for transportation, and arrived early to help orient them. They acknowledged these accommodations.

We ensured the session's objectives and activities that would take place were clear. We actively facilitated the engagement of all members to mitigate perceived power differentials, and used a deliberative process for decision-making, discussing ideas until consensus was reached. In some instances, two meetings were required to reach consensus, usually because additional information was required to make the decision. During small-group discussions, tables had a mixture of members from the various groups to ensure the sharing of ideas. To reinforce the value of the guidance we received, we began each meeting by reviewing the decisions and recommendations from the previous meeting and reporting on the actions taken. Members implicitly adopted values that enabled equitable collaboration, showing great openness to hear all voices and valuing everyone's perspectives. One patient partner (K.J.) noted that participating individuals with lived experience were treated like full members of the team and were able to bring a different level of understanding to the project because of their experience, identifying areas the team might not otherwise have considered. 
The patient partners provided crucial guidance across the feasibility research cycle and the RCT development. For example, when designing the navigation model, they guided the navigator role and scope of responsibilities, and advocated for specific personal attributes, such as the importance of communication in eliciting the priorities of patients, because this would promote the likelihood that patients would be fully engaged in their self-care. When the partnership reached an impasse on whether to define the primary study outcome - accessing the resource - as having used the service or whether having an upcoming appointment or being on a waiting list was acceptable, it was a patient partner who provided the input that allowed the group to reach consensus. They edited the study documentation intended for patients, and reviewed the referral and consent forms, survey questionnaires and promotional material for literacy level, appropriateness of the language for sensitive issues, clarity and comprehensiveness. They contributed to the result interpretation, shedding light on potential reasons for emerging findings that suggest that the likelihood of achieving access is influenced by the patient's profile and need being addressed.

We believe that the face-to-face partnership meetings involving all groups of stakeholders led to better-informed decisions than consultations with each group separately, because each member's contribution was informed by the views expressed by others. We found that an element of disagreement expressed frankly and respectfully is useful. For example, the partnership had an ardent discussion about the definition of the control arm. The arm was to be usual care (i.e., no active intervention from the study). However, the patient partners and some care providers expressed concern that patients directed to the study might not receive the guidance for accessing the needed service the provider might otherwise have given their patients under usual care. This would be especially worrisome for patients with a more acute need, such as those requiring mental health services. During the discussions, primary care providers shed light on what would likely take place during their encounters when such a referral is made. Researchers explained the importance of minimizing the level of active intervention. The consensus, satisfactory to all, was to direct these patients to "Ontario 211," a provincial navigation service that provides information about available resources and which authorities hope will become part of providers' usual care.

As with any collaboration, all recommendations would not be implemented. For instance, one individual with lived experience argued that the navigator's sociomedical and cultural profile should be concordant with that of the patients they serve. Indeed, peer support is more beneficial to patients than support from individuals without similar experience, particularly for mental health and addiction services. ${ }^{10}$ However, our navigation model is meant to be open to a broad patient population, and considering all options, everyone agreed that this would not be feasible.

We have retained lessons from the feasibility study that we rectified in the RCT. Specifically, we had not explicitly established roles, time commitment or compensation for patient partners at the outset. This emerged tacitly over time. We did not have a clear idea of the first two and did not have the funds for the latter. We did not actively discuss values and principles that the partnership would uphold to support equitable contribution by all. Fortunately, collegial collaboration emerged naturally.
This project reinforced for us the value of working in a collaborative partnership that includes individuals with lived experience. The open and respectful dialogue that took place across all members allowed for a much richer conversation and better-informed decisions. We believe that, as a result of the partnership, the navigation model developed is much more likely to be responsive to patient needs, acceptable to care providers and has greater potential for scalability by decision-makers.

\section{References}

1. Pennant M, Davenport C, Bayliss S, et al. Community programs for the prevention of cardiovascular disease: a systematic review. Am J Epidemiol 2010;172:501-16.

2. March S, Torres E, Ramos M, et al. Adult community health-promoting interventions in primary health care: a systematic review. Prev Med 2015;76:S94-104.

3. CMA position statement: ensuring equitable access to care: strategies for governments, health system planners, and the medical profession, health system planners, and the medical profession. Ottawa: Canadian Medical Association; 2013. Available: www.cma.ca/Assets/assets-library/document/en/advocacy/ PD14-04-e.pdf (accessed 2018 Oct. 10).

4. Creating a healthier Canada: making prevention a priority. Ottawa: Public Health Agency of Canada; 2010. Available: www.phac-aspc.gc.ca/hp-ps/hl-mvs /declaration/pdf/dpp-eng.pdf (accessed 2018 Oct. 10).

5. 2012 Annual Report. Toronto: Office of the Auditor General of Ontario; 2012. Available: www.auditor.on.ca/en/content/annualreports/arbyyear/ar2012.html (accessed 2018 Sept. 27).

6. Fiscella K, Shin P. The inverse care law: implications for healthcare of vulnerable populations. J Ambul Care Manage 2005;28:304-12.

7. Nápoles AM, Gregorich SE, Santoyo-Olsson J, et al. Interpersonal processes of care and patient satisfaction: Do associations differ by race, ethnicity, and language? Health Serv Res 2009;44:1326-44.

8. Building patient engagement in research: a guide for research teams. INSPIRE-PHC Patient Engagement Resource Centre (PERC); 2017. Available: www.patient engagement-phcresearch.com/copy-of-framework (accessed 2018 Oct. 10).

9. McMaster Health Forum. Masterclass. Hamilton: McMaster University; 2018. Available: www.mcmasterforum.org/learn-how/system-leaders (accessed 2018 Oct. 10).

10. Repper J, Carter T. A review of the literature on peer support in mental health services. J Ment Health 2011;20:392-411.

More information on this project is available at www.ossu.ca/ IMPACTAwards.

\section{Competing interests: None declared.}

This article was solicited and has been peer reviewed.

Affiliations: Department of Family Medicine (Dahrouge), University of Ottawa, Ottawa, Ont.; patient partner (James), Ottawa, Ont.; Centre for Rural and Northern Health Research, (Gauthier), Laurentian University, Sudbury, Ont.; Telfer School of Management (Chiocchio), University of Ottawa, Ottawa, Ont.

Contributors: All authors have contributed substantially to the manuscript, writing sections and reviewing and critically revising all parts of the manuscript. They have all approved the final version of the manuscript and are accountable for the information reported.

Funding: This project was supported the Canadian Institutes of Health Research (in partnership with the Australian Primary Health Care Research Institute) Team Grant "Community-based primary healthcare innovative models promoting access and coverage team (IMPACT)" (July 2013 to March 2018) and the Ontario SPOR SUPPORT Unit IMPACT award "Navigation implementation and support to optimize access to appropriate community services for Francophones living in minority situations (access to resources in the community [ARC])" (April 2016 to April 2020, \$873049). The funders operate at arm's length in this initiative.

Correspondence to: Simone Dahrouge, sdahrouge@bruyere.org 